\title{
Offenders with intellectual disabilities in prison: what happens when they leave?
}

Glynis H. Murphy, PhD, g.h.murphy@kent.ac.uk

University of Kent, Tizard Centre, Giles Lane, Canterbury, CT2 7LR, UK

Pak Chiu, MA, pak.I.chiu@gmail.com

University of Kent, Tizard Centre, Giles Lane, Canterbury, CT2 7LR, UK

Paraskevi Triantafyllopoulou, PhD, P.Triantafyllopoulou@kent.ac.uk

University of Kent, Tizard Centre, Giles Lane, Canterbury, CT2 7LR, UK

Magali Barnoux, PhD, M.Barnoux@kent.ac.uk

University of Kent, Tizard Centre, Giles Lane, Canterbury, CT2 7LR, UK

Emily Blake, PhD, E.Blake@kent.ac.uk

University of Kent, Tizard Centre, Giles Lane, Canterbury, CT2 7LR, UK

Jennifer Cooke, MA, jc594@kent.ac.uk 
University of Kent, Tizard Centre, Giles Lane, Canterbury, CT2 7LR, UK

Rachel V.E. Forrester-Jones, PhD, R.V.E.Forrester-Jones@kent.ac.uk University of Kent, Tizard Centre, Giles Lane, Canterbury, CT2 7LR, UK

Nick J. Gore, PhD, n.j.gore@kent.ac.uk

University of Kent, Tizard Centre, Giles Lane, Canterbury, CT2 7LR, UK

Jennifer K. Beecham, PhD, J.K.Beecham@kent.ac.uk

University of Kent, PSSRU, Canterbury, CT2 7LR, UK

Key words: Intellectual disabilities, offenders, prison, follow-up 


\begin{abstract}
People with intellectual disabilities, if convicted of offences, may be sentenced to prison, but little is known about their life when they are released. This study followed up men with ID who were leaving prisons in England. The men were hard to contact, but 38 men were interviewed, on average 10 weeks after leaving prison. The men were living in a variety of situations and often were very underoccupied, with limited social networks. $70 \%$ were above the clinical cut-off for anxiety and $59.5 \%$ were above the clinical cut-off for depression. The men were receiving little support in the community and many had been re-interviewed by police. Community teams need to provide better support to this very vulnerable group.
\end{abstract}




\section{Introduction}

Increasingly, in developed countries, people with intellectual disabilities (ID) are living as ordinary citizens, in communities, with some support. Occasionally, of course, any citizen may break the law and this also applies to citizens with ID. An inevitable consequence is that, in all countries where this has been studied, some of the people in the criminal justice system (CJS) have been found to have intellectual disabilities. The precise prevalence of ID in the CJS is hard to establish and is much disputed. Suffice it to say that most studies find people with ID are somewhat overrepresented as suspects in police stations (Gudjonnsson, Clare, Rutter, \& Pearse, 1993; Lyall, Holland, Collins, \& Styles, 1995), in courts (Hayes, 1993; Hayes 1996; Vanny, Levy, Greenberg, \& Hayes, 2009) and on probation (Mason \& Murphy, 2002a, 2002b).

In prisons, the picture is less clear: prevalence figures for ID in prisons tend to fall between 0\% (as in a UK study by Murphy, Harnett \& Holland, 1995) to around $10 \%$ (e.g., in a large USA study by Brown \& Courtless, 1971; and one in Norway by Sondenaa, Rasmussen, Palmstierna \& Nottesstad, 2008 ), but occasional figures have been much higher (such as 19\% in a study in Canada by Crocker, Cote, Toupin, \& St Onge, 2007). There is variation both across jurisdictions, and within jurisdictions (see Murphy \&Mason, 2014, for a review), and the variations are likely to result from a host of methodological issues (i.e., sample tested, the assessment measures used) and legal issues (for example, opportunities to divert people with ID from custody in a particular jurisdiction). Fazel, Xenitidis and Powell (2008), in a large meta-analysis, concluded that the true prevalence of ID in prisons is between 0.5 and $1.5 \%$ and that people with ID are not over-represented in prisons.

Whatever the exact prevalence of people with ID in the CJS, there is general agreement that people with ID are disadvantaged in police stations, courts, probation and prisons (Murphy \& Mason, 2014), mainly as a result of their communication difficulties. These make it difficult for them to understand their rights in the police station (Clare \& Gudjonsson, 1991 \& 1995; Fulero \& Everington, 1995; O'Connell, Garmoe, \& Goldstein, 2005), to understand proceedings in court, to 
face cross-examination in court (Kebbell \& Hatton, 1999; Perlman, Ericson, Esses, \& Isaacs, 1994), and to understand the rules and fill in forms (e.g., to book appointments for doctors or for family visits) in prisons (Talbot, 2008).

Most of the people with ID who get involved in the criminal justice system have only mild intellectual disabilities, since most jurisdictions exclude those with severe ID from the CJS. Generally speaking, the characteristics of those with ID in the CJS include being mostly young and male, having a background of social deprivation and family breakdown, often being themselves the victim of abuse in the past, low rates of literacy and employment, and high rates of mental health needs (Barron, Hassiotis, \& Banes, 2004; Hassiotis, Gazizova, Akinlonu, Bebbington, Meltzer, \& Strydom, 2011; Lindsay et al., 2010; Wheeler et al., 2009). In some countries minority ethnic groups are overrepresented (Hayes, 1996). Several studies have demonstrated that all of this makes offenders with ID very similar in terms of their backgrounds to non-disabled offenders (MacEachron, 1979; Barron et al., 2004; Cockram, 2005a; Crocker et al., 2007). The types of offences committed include property crimes, verbal and physical aggression, sexual offences, and other offences, and these seem similar to the range of offences of other offenders (Barron et al, 2004; Cockram, 2005a; Glaser \& Deane, 1999; MacEachron, 1979; Crocker et al., 2007), though some have argued that drug offences and car crimes are less common amongst those with ID (Cockram 2005a; Holland \& Persson, 2011).

What is very unclear, from previous research, is how prisoners with ID fare after leaving prison. This is an important topic, for if they simply reoffend and return to prison, there may be a need for better community support and improved policies. Previous studies do not seem to have focused on this issue, despite the fact that there are numerous studies of re-offending in non-ID samples (see Cunliffe \& Shepherd, 2007, for a review). An early study in Denmark of offenders with ID on care orders suggested very high reoffending rates of around 70\% in a year (Lund, 1990), and a small study by Barron el al. (2004), of 61 offenders with ID in an area of North East London and 
Essex, also showed a high re-offending rate of about $50 \%$ in less than a year. Meanwhile a study of recidivism by Gray, Fitzgerald, Taylor, MacCulloch, and Snowden(2007), of people with ID and offending behaviours released from secure services in the UK, showed low rates of re-offending for those with ID (4.8\% after 2 years), lower than for those without ID. However, none of these three studies was specifically about offenders being released from prison. A larger Australian study did track offenders with and without ID over a period of eleven years (Cockram, 2005b), and reported that those with ID had a higher likelihood of re-arrest than those without ID, but the study gave very little information on services.

In this study, men with ID were recruited while currently in prisons in England, and they were followed prospectively once they left prison. Given that this was the first study of its kind in the UK, and given that most offenders with ID are male, it was decided to focus only on male offenders with ID. This study thus had the following aims:

- To follow up men with ID when they leave prison

- To assess their quality of life and mental health after leaving prison

- To discover whether, and how, they were supported following prison

- To examine CJS contacts and re-offending after leaving prison

The plan was to follow men up twice: firstly one month after leaving prison (time 1), and then again 9 months later (time 2). This paper reports the data from the first follow-up at time 1.

\section{Method}

In the UK, there has been considerable discussion of the disadvantages suffered by people with ID (and people with mental health needs) in the CJS, and a recent, very influential, government report (the Bradley report, Department of Health, 2009), made a number of recommendations in relation to people with ID and/or mental health needs in the CJS. Amongst the 85 recommendations 
made was the proposal that all prisoners should be screened for ID, since no prisons were routinely conducting such screening at the time of the Lord Bradley enquiry (Talbot, 2008). Subsequently, a study commissioned by the Department of Health, of screening for ID of over 3000 prisoners in three English prisons, showed that such screening was certainly feasible (Murphy, Gardner, \& Freeman, 2015). It was anticipated, following the Bradley report, which the government accepted, that the roll-out of such screening would be an ideal opportunity for the current study. In the event, screening did not become routine and all prisons taking part in this study only screened a small number of prisoners for ID (this issue is returned to in the discussion). The screening that did occur took place through health care in the prisons and so contact was made through the healthcare services in the prisons, once prison governors had agreed that a particular prison could take part.

\section{Participants}

Following ethical approval (see below under Procedure), a number of male prisons in the South East, South West, Midlands, North West of England, and their associated NHS Trusts or other healthcare providers were contacted and asked to take part in the study. They were asked to refer men with ID to the project, if they consented to participation in the project in principle and were due to leave prison within the next few months. The researchers then went to the prison to provide accessible information sheets and consent forms to each of the prisoners proposed, to take formal consent, check they had screened positive for ID (on the LDSQ, McKenzie \& Paxton, 2006), and to take a note of likely contact numbers for them for when they were released. On a few occasions where it turned out that suitable men had just left prison, their local healthcare team was contacted (following approval from the ethical review body to this minor adjustment to the protocol), and a similar process took place. 
Overall, 24 prisons gave approval for the research and 22 healthcare organisations were approached, of which 17 gave R\&D approval (some health care organisations covered several prisons). Not all of these organisations were able to provide potential participants, however.

In total, 88 men were referred to the project, from 19 prisons and 14 healthcare organisations. Of these 88 men, 19 did not meet the criteria (i.e., either because they did not have ID or because they were on a long sentence and would not be released during the time of the project). Only 1 man initially declined to consent.

Once the men had left prison, they were extremely hard to contact (see below under Procedure). 19 men were lost to contact before the first interview could be arranged, and 10 men later withdrew their consent, either before engaging in an interview or after doing part of an interview but not completing it (see Figure 1). Of the forty men remaining, two had been out of prison so long that they were too late for Time 1 interviews, so in all 38 men completed their Time 1 interviews.

Figure 1 about here

For each man a member of staff was also interviewed, where he/she consented and where this was possible, to check information the man had given (i.e., his address and contact numbers, his daily activities, his support services, his crime, any further CJS contacts and their estimate of risk of re-offending). Usually these staff were probation officers or staff in probation hostels or healthcare staff (e.g. from the community learning disability teams). 25 staff were interviewed in this way; for the remaining men staff did not agree to being interviewed or there were no staff in touch with the man to be asked.

\section{Measures}

The interview with the men, both at time 1 and time 2, gathered basic demographic data (i.e., age, ethnicity, marital status, crime, length of sentence, current living situation) and asked men 
about their lives in general, their daily activities (including volunteering, supported employment, work or other regular activities) and their social networks, using the Social Network Guide. This latter measure was developed from Tracy and Abell (1994) and adapted for a previous ethnographic study of people with mental illness (Forrester-Jones \& Grant, 1997), being also used later for quantitative studies of people with intellectual disabilities and mental illness (see Forrester-Jones et al., 2006; 2012). It maps structural (size, membership and density), interactional (i.e., reciprocity, frequency, duration and closeness) and supportive (e.g. companionship and decision-making) components of individuals' networks. For each identified member, the type of relationship (e.g., family, staff and neighbour) is noted.

The men then completed the Client Service Receipt Inventory or CSRI (Beecham \& Knapp, 2001) which logged their service contacts, including those with primary care, community learning disability teams, social workers, criminal justice workers, and others. The men's mental health was assessed on the Glasgow Anxiety Scale (Mindham \& Espie, 2003), which has 27 items relating to general and specific anxieties, each rated on a 3 point scale (never, sometimes or always), and the Glasgow Depression Scale (Cuthill, Espie, \& Cooper, 2003), which has 20 questions relating to depression, each rated on a 3 point scale (never, sometimes or always).. Both of these scales were designed specifically for people with intellectual disabilities, both have good internal consistency, test-retest reliability and concurrent validity (Mindham \& Espie, 2003; Cuthill, et al., 2003). The recommended cut-off for clinically significant anxiety is 13 or above and for clinically significant depression is also 13 or above. Finally, the men rated their satisfaction with their quality of life on Cummins' ComQol-A5 satisfaction scale (Cummins, 1997). The ComQol satisfaction scale required the men to rate on a seven point scale, running from 'delighted' to 'terrible', how satisfied they felt with seven aspects of their lives (i.e., the things they owned, their health, their achievements, their close relationships, how safe they felt, doing things outside the home and happiness). 


\section{Procedure}

Given that men were initially being contacted through healthcare services in prisons, the study was submitted for NHS ethical approval. It was also submitted to the National Offender Management Service (NOMS), since prisons were involved. Following ethical approval from these two bodies, research governance approval was sought from every relevant NHS Trust or private healthcare provider and prison governor. Once approved by these bodies, men who were deemed suitable (i.e., had been screened positive for ID and were leaving prison within the next few months) were told about the project in principle and asked if they might like to take part. If they indicated that they might, the researcher went to the prison to take formal consent, using accessible information sheets and consent forms. Only those with capacity to consent and who did consent were included.

During the consent process, provided the man did consent, the researcher took contact details of where or with whom the man might be living once he left prison. This was extremely difficult. Men in prison are not allowed to have mobile telephones, so their telephone numbers were not typically available. Some were clear that they would live with their families (usually parents), and some knew their parents' telephone numbers or addresses; others were totally unsure where they would be living. For these latter, the contact numbers for any family members, friends, learning disability team members, and other contacts were taken, if the men could remember them. The men were also given a wrist band and a small card with the project's telephone number on and they kept their consent forms, which included the project's telephone numbers. The researchers took a note of when the men were expecting to leave prison and contacted the prison to find out if they had actually left on the appropriate date, and to obtain an address for the man. However, prisons often released the men earlier or later than predicted and could sometimes not provide contact addresses. In many cases, once they left prison, men had probation officer oversight, but not all 
probation officers agreed to contact the researchers or to talk to them when researchers contacted them. Consequently some men were lost to follow-up.

When men did remain in contact, researchers arranged to meet them to interview them, if possible one month after their release from prison. Where men had provided phone numbers to the researchers, they kept in regular monthly contact in order to try to reduce the number lost to followup. Nevertheless, the mean length of time between leaving prison and being interviewed at time 1 was considerably longer than one month, especially for some men (see below and Figure 1 for details).

\section{Results}

Forty men who had consented were traced. For two of these men, it took so long to track them down that they were considered to be lost for Time 1 but present for Time 2: they were traced 39 weeks and 57 weeks after leaving prison respectively (so their data do not appear here). For the remaining 38 men, the Time 1 interviews took place on average 10.4 weeks after leaving prison $(M=$ $10.40 ; S D=7.71)$. These men's ages ranged from 19 to 64 years and they were on average 33yrs old $(M=33 ; S D=10.40)$, were mostly of white ethnicity $(89.5 \% ; n=34)$, and were single $(86.8 \% ; n=33)$, rather than in a close relationship. They came from 17 different prisons, covered by 12 different healthcare providers, and had been convicted of a variety of crimes, for which they mostly received short sentences - see Table 1 .

\section{Table 1 about here}

The men's living situations were very varied at Time 1 interviews - see Table 2 . About one third were living with family members or on their own $(n=12)$, about another third were in probation hostels ( $n=8)$ or residential homes of one kind or another with 24 hour staffing $(n=3)$, about a quarter were in secure hospital services $(n=8)$, very few were in supported living $(n=3)$, and some $(n=4)$ were already back in prison. 
About a fifth of the men $(n=7)$ had already lived in more than one place since leaving prison, even though the T1 interview was only 10 weeks, on average, after first leaving prison. Of these 7 men who had already moved at least once, 4 had gone back into prison after living independently or with families/friends with little or no support, and one had gone into a secure unit after living with his brother and feeling unable to cope (of the other two, one was moving out of a probation hostel to live with family, and one was moving out of a distant secure unit to one nearer the family).

Living situations did not seem to be statistically significantly associated to the lengths of sentences that the individuals had served, nor to the type of crime they had committed: for example, 11 of the 26 men who had served short sentences, of under one year, were living in the least restrictive settings (i.e., alone or with friends or family), while 10 of the 26 were living in the most restrictive settings (secure units or back in prison), the remainder (5) being in residential group homes or probation hostels.

Table 2 about here

In general, the men were grossly under-occupied. Only $10.5 \%$ of men $(n=4)$ were in any kind of employment (two of these were already back in prison and were working in the prison), with a further $15.8 \%(n=6)$ engaged in at least some volunteering. As regards 'activities', shown in Table 3 , these were only counted if they were specifically scheduled and they mostly involved leaving the house, so for example, getting dressed, washing up, or watching TV were not counted, whereas going shopping, doing work experience, volunteering in a local charity shop, attending an in-house group meeting, going to a meeting with probation, going fishing, were counted in half-day blocks (where activities took less than half a day, e.g. food shopping, they were counted as half a day; where activities took a whole day, e.g. a whole day's volunteering, it was counted as two half-days). The average numbers of activities in weekdays, evenings, and at weekends are shown in Table 3, and it can be seen that most men had little structure in their lives, especially at weekends. 
For example, two men had no structured activities whatsoever in the week, and two others had only one activity per week (in both cases, it was going to see their probation officer). On the other hand, of those with more activities, one man volunteered every weekday, all day, on a farm (funded by social services) and he went out once at weekends with family members ( $n=11$ activities); another worked all day with his father, painting and decorating and had several activities with his family in the evenings and at weekends ( $n=15$ activities); another volunteered at a number of different projects and played various sports, including badminton, skittles and 5 -a-side football ( $n$ = 16 activities); another was back in prison by the time of his time 1 interview but was working in the laundry ( $n=10$ activities). Overall, $63 \%(n=24)$ of the men said they did not have enough to do and $87 \%$ could name things they would like to do, which were perfectly feasible (e.g., working with animals, going to the cinema, going to the gym). Only 5.3\% went to college for any sessions at all ( $n=$ $2)$, but $21 \%$ said they would like to attend college $(n=8)$. Living situation may have an effect on activity levels, and levels were somewhat higher in restricted settings and lower in family settings, but when living situation was classified as very restricted (prison or secure unit), somewhat restricted (probation hostel or residential home) or less restricted (living alone or with family), there was no significant difference between mean numbers of activities and degree of restriction of living environment, on ANOVA $(F(2,38)=2.65, p>0.05)$.

\section{Table 3 about here}

The men's social networks were often very limited, compared to those of the general population. Despite being able men with only mild intellectual disabilities, their social network size ranged from 4 to 145 and was on average 29.1 in size $(M=29.1 ; S D=27.20)$ and six people had 7 or fewer people in their social network (see Table 4). Where networks were large, men were often in secure provision or prison. There was a relationship between the size of the men's social networks and degree of restriction of living environment: networks were significantly larger, on ANOVA, for those who were in secure units or back in prison $(M=45.2 ; S D=39.8)$, compared to probation 
hostels or residential group homes ( $M=26.2 ; S D=14.7)$, and compared to living at home or with family $(M=18.4 ; S D=14.3)-F(2,38)=3.821, p<0.05$

\section{Table 4 about here}

The men were often struggling with anxiety and depression, and $47 \%$ reported being on medication for their mental health. The mean score on the Glasgow Anxiety Scale was $18.8(M=$ $18.80 ; S D=9.70)$, and $70.3 \%$ of the men were scoring above the clinical cut-off of 13. On the Glasgow Depression Scale, the mean score was $14.5(M=14.50 ; S D=7.70)$ and $59.5 \%$ were scoring above the clinical cut-off of 13 . Levels of anxiety and depression were highly correlated with each other (Spearman's rho $0.78, n=37, p<0.001$ ) but there was no relationship between levels of anxiety and depression and the total numbers of activities men were involved in each week (Spearman's rho $0.08, n=37, p=0.63$, and $0.06, n=37, p=0.74$, respectively). Nor were there differences between levels of anxiety and depression and the degree of restriction of their living environments, so contrary to expectations, those in secure units were not more depressed or anxious than others (on ANOVA, F $(2,37)=0.20$ and $F(2,37)=0.54$ respectively, both $p>0.05)$. In addition, 15 of the 38 men $(40 \%)$ had difficulties involving alcohol and/or drugs, in that these substances were thought to be important risk factors for their past or future offending (according to the men themselves and/or their staff). Despite the levels of anxiety and depression, and difficulties resisting alcohol and drugs, the men's median satisfaction with various aspects of their quality of life was either 'mixed' (4) or 'mostly satisfied' (5), see Table 5. Those living alone or with families tended to be more satisfied with the things they owned, their health and close relationships, but none of the seven aspects of their degree of satisfaction with their lives related significantly to the degree of restriction of their living situation (by Kruskal Wallis non-parametric analysis).

Table 5 about here 
More than half of the men had a probation officer $(n=22)$, who they tended to see once a week or once a fortnight. Half of the men ( $n$ 19) had a care manager/social worker (i.e., though most men seemed very unsure about this), and 22 had contacts with specialist health professionals (i.e., nurses, psychologists or psychiatrists on intellectual disabilities teams) during the time they were out of prison. Those with probation officers tended to be the ones who did not have healthcare support, and vice versa. In addition, more than half of the men $(n=21)$ had been in contact with the police since leaving prison, and eleven had been formally questioned by the police about offences. Of these 11, 8 spent nights in police cells and 8 appeared in court, 7 ending up with further convictions. Having a care manager/social worker or a probation officer did not seem to protect men from having contact with the police, but having health care worker contacts while out of prison was associated with a significantly reduced likelihood of police contacts $\left(\chi^{2}(1,38)=4.35, p=<0.05\right)$, though this is based on a small sample so should be cautiously interpreted. Of the 7 men who had further convictions by the time of the T1 interviews, there were 4 cases of burglary/stealing, one of criminal damage and two of breached licence conditions ( 4 of these 7 men were the ones who were now back in prison).

\section{Discussion}

The men with ID who consented to take part in the study were mostly young and single and had committed crimes that attracted short sentences. Thus they had characteristics, in terms of age, marital status, and crimes, that were no surprise given previous studies of men with ID in prisons in the UK, Canada, America, Australia, and Norway (MacEachron, 1979; Crocker et al, 2007; Cockram, 2005a; Holland \& Persson, 2001; Sondenaa et al, 2008; Murphy \& Mason, 2014). On leaving prison, they went to a surprising variety of living situations, from the very restrictive (e.g., secure units) to the very unrestrictive (e.g., living alone or with family), and this did not appear to correlate with the seriousness of their crimes. In some areas of the country, healthcare staff informed the project that 
they were trying to establish a logical care pathway for people with ID leaving prison, so that people could be transferred to a secure unit (and then leave to go to a 24-hour staffed home, and then gradually go to less restrictive settings). Thus for these men in this study, their place of residence was still in the secure unit. Nevertheless, this did not seem to be a typical path for most parts of the country, and it often seemed very arbitrary where a person went to live, determined by factors such as whether they had family members who would take them in, rather than by standardised risk assessments or by degrees of mental health difficulties. Cockram (2005a, 2005b) found an even higher percentage of ID offenders went to live with families on release from prison (about 50\%) but this may have been because her follow-up period was longer than in the current study. It is thought that good family support protects people with ID from engaging in further crimes, as has been suggested by Wheeler et al (2014), but it is also true that conflict with families is not a protective factor (Wheeler et al, 2014), so services should not assume that settling a man back with his family is necessarily a good solution when he leaves prison.

Once placed in a setting, it appeared that many men had very little to do, even though this has been shown to be linked with offending (Wheeler et al, 2014). Extremely few men in this sample were working (even for a few hours per week) and only a small number were volunteering, as Cockram (2005b) also found. However, given that rates of employment for all people with ID are very low in the UK (of the order of 10\%), compared to people without ID, it is perhaps not surprising that even fewer with offending histories obtained jobs. Nevertheless, given the consistent evidence that employment protects against re-offending in the general population (Soothill \& Holmes, 1981; Uggen, 2000) and in the population with ID (Wheeler et al, 2014), it would seem important for men with ID to be occupied in structured activities even if they do not work. But the reality was that many men were extremely under-occupied, with the average number of half days with any structured activity whatsoever being only 4 (out of 10 ) on weekdays. There were, nevertheless, 
some men who had very good structured programmes (such as the man who worked on a farm every day, funded by social services, and the man who worked on building and decorating with his father), showing that with good support from families and/or community intellectual disability teams, productive days are possible. Interestingly, there was no significant association between structured programmes and the degree of restriction of the living situation, nor with degree of depression and anxiety.

The estimated average size of social networks for the general population is 124 (Hill \& Dunbar, 2003), with Dunbar (1993) suggesting that humans have the 'cognitive capacity' to hold social groupings of around 150 contacts. The men in this study however, had very limited social networks $(M=29)$, which were sometimes shockingly small (six men had 7 contacts or less), given that they had only mild ID. Using the same instrument (the Social Network Guide), Forrester-Jones et al. (2004) found the average network size of adults with mild to moderate ID to be 36 , with this figure increasing to 42 once these individuals had been in supported employment for one year. Whilst still falling far short of general population estimates, the supported employment group in the Forrester-Jones et al study were faring far better than those in the present study. The average social network size of the men in this study was more akin to that found for adults with more moderate to severe ID (average network size $=22$ ) who had experienced deinstitutionalisation and were now living in the community (Forrester-Jones et al. 2006). It seemed that the men living with families, or alone with some support, had the smallest networks, as social network size was associated with degree of restrictiveness of the living situation. This no doubt resulted from the fact the most restrictive settings tended to be large units. However, it was also striking that some men living with families described being ostracised by the local communities, sometimes to the extent of having abusive graffiti drawn on the house walls. This illustrates the difficulty of living with the dual stigmatisation of intellectual disabilities and a history of offending. 
Many men seemed to be in a rather fragile mental state. The levels of depression, anxiety and alcohol/substance misuse were extremely high, even though most men said they had felt worse when in prison. Hassiotis et al (2011) also reported high levels of mental health problems for men with ID in prison, while a number of researchers have commented on the high rates of alcohol misuse amongst offenders with ID (see Lindsay et al (2013) for a review). Given the high rates of anxiety and depression amongst the men in this study, it was surprising that only about half had any contact with specialist health services (i.e., community intellectual disability teams) and it was not unusual for probation officers to complain that they had referred the men to the community intellectual disability teams but been told they were not eligible for support. The men who were receiving such community intellectual disability team support did appear to be less likely to be in contact with the police, though caution should be exercised in generalising from such a small sample.

Overall, more than half of the men had been in contact with the police since leaving prison, and over half of these had been formally questioned about further crimes and/or breaking the conditions of their parole/licence. Even though the Time 1 interviews took place on average only 10 weeks after leaving prison, four men were already back in prison. Cockram (2005b) also found very high rates of re-offending in her sample of men with ID released from prison, as did Lund (1990) and Barron et al (2004), though their samples were not released specifically from prison. It is difficult to compare the reconviction rates for this study to those in non-ID populations, as the rates of reconviction vary with the jurisdiction, the age of the person, the original offence, the history of offences and of course the time since leaving prison (Cunliffe and Shepherd, 2007; Ministry of Justice, 2016). Suffice it to say that the general reconviction rate (within a year) in the UK is $24.5 \%$ (all disposals), while for those leaving prison it is 34.5\% (Ministry of Justice, 2016). The follow-up of this cohort at Time 2 should give a better idea about whether those with ID are more frequently reconvicted. 
The implications for services, however, are already very clear: they need to do better. In the UK, social care is the lead agency for people with intellectual disabilities. All men with intellectual disabilities, prior to release from prison, should have an allocated care manager who should meet with them, face to face (i.e. not just be a contact name on paper). It should be obligatory for social care to be involved, and they should not be allowed to argue that the person's mild degree of intellectual disability makes them ineligible for services. The care manager should plan with them where they should live, what they should do during the day, how they should receive support and/or treatment for mental health needs or other difficulties, to reduce their risk of re-offending. The care manager should also liaise with the probation services, where they are involved, and with the local community intellectual disability health team (if this is not already a joint social care/health care team), and they should also ensure family liaison. All too often services operate in 'silos', with criminal justice services (police, prison, probation) not communicating with health teams, and health teams not communicating with social care.

This study, though one of the first of its kind, had some limitations. It was a small study, far smaller than planned, because of the difficulties of recruiting participants in prisons and tracking them once released. It was not possible within the resources of the study to recruit a non-disabled comparison group but similar studies of non-disabled prisoners, for example, Byng et al.'s (2012) study of the health of prisoners released from prison, had even greater drop-out rates (i.e., only $27 \%$ of Byng's 313 people referred to the project were interviewed at the first follow-up), so that it seems likely that this group of people, with their chaotic lives, are a very difficult group to recruit and to track. It is also possible that the difficulty of keeping track of people is not randomly distributed. For example, in this study it may be that more of those living alone were lost to follow-up, compared to those living with family or with staff.

Despite the limitations of this study, what is clear is that this is a group of very vulnerable people. They have high rates of mental health needs, relatively poor social networks and 
unstructured days, and high rates of re-arrest by the police. Nevertheless, what was also apparent was that in some parts of the country, where social services, probation and health worked together, very successful resettlement did take place. 


\section{Acknowledgements}

We would like to thank all the men who took part in this study, and the staff who we interviewed, as well as the prisons and community teams who participated. We are grateful to SSCR for funding the study. 


\section{References}

Barron, P., Hassiotis, A., \& Banes, J. (2004). Offenders with intellectual disability: a prospective comparative study. Journal of Intellectual Disability Research, 48 (1), 69-76. doi: 10.1111/j.1365-2788.2004.00581.x

Beecham, J., \& Knapp, M. (1992). Costing psychiatric interventions. In G. Thornicroft, C.R.Brewin \& J. Wing (Eds.), Measuring Mental Health Needs (pp. 163-183). London: Gaskell.

Brown, B.S., \& Courtless, T.F. (1971). The Mentally Retarded Offender. Washington DC: U.S. Government Printing Office, Dept of Health Education and Welfare Publication No. 72-90-39. doi: $\underline{10.1037 / e 520882009-001}$

Byng, R., Quinn, C., Sheaff, R., Samele, C., Duggan, S., Harrison, D., . . Campbell, J. (2012). COCOA: Care for Offenders Continuity of Access. Final report, NIHR Service Delivery and Organisation Programme, Project 08/1713/210, NIHR. Retrieved from http://socialwelfare.bl.uk/subjectareas/services-client-groups/adultoffenders/nihrhealthservicesanddeliveryresearchprogramme/1542302012_SDO_FR_081713-210_V01.pdf

Clare, I.C.H., \& Gudjonsson, G.H. (1991). Recall and understanding of the caution and rights in police detention among persons of average intellectual ability and persons with a mental handicap. Issues in Criminological and Legal Psychology, 17 (1), 34-42.

Clare, I.C.H., \& Gudjonsson, G.H. (1995). The vulnerability of suspects with intellectual disabilities during police interviews: a review and experimental study of decision-making. Mental Handicap Research, 8 (2), 110-128. doi: 10.1111/j.1468-3148.1995.tb00149.x

Cockram, J. (2005a). People with an intellectual disability in the prisons. Psychiatry, Psychology \& Law, 12 (1), 163-173. doi: 10.1375/pplt.2005.12.1.163

Cockram, J. (2005b). Careers of offenders with an intellectual disability: the probabilities of rearrest. 
Journal of Intellectual Disability Research, 49 (7), 525-536. doi: 10.1111/j.1365-

\section{$\underline{2788.2005 .00707 . x}$}

Crocker, A.G., Cote, G., Toupin, J., \& St-Onge, B. (2007). Rate and characteristics of men with an intellectual disability in pre-trial detention. Journal of Intellectual \& Developmental Disability, 32 (2), 143-152. doi: $\underline{10.1080 / 13668250701314053}$

Cummins, R.A. (1997). Comprehensive Quality of Life Scale - Adult Manual. $5^{\text {th }}$ edition. School of Psychology, Deakin University, Australia.

Cunliffe, J. \& Shepherd, A. (2007). Re-offending of adults: results from the 2004 cohort. Research, Development and Statistics Directorate, Home Office, UK.

Cuthill, F.M., Espie, C.A., \& Cooper, S.A. (2003). Development and psychometric properties of the Glasgow Depression Scale for people with a learning disability. British Journal of Psychiatry, 182 (4), 347-353. doi: 10.1192/bip.182.4.347

Department of Health. (2009). Lord Bradley's Review of People with Mental Health Problems or Learning Disabilities in the Criminal Justice System. Retrieved from www.dh.gov.uk/en/Publicationsandstatistics/Publications/PublicationsPolicyAndGuidance/D H_098694.

Dunbar, R.I.M. (1993). Coevolution of neocortical size, group size and language in humans. Behavioural and Brain Sciences, 16 (4), 681-735. doi: 10.1017/s0140525×00032325

Fazel, S., Xenitidis, K., \& Powell, J. (2008). The prevalence of intellectual disabilities among 12000 prisoners: a systematic review. International Journal of Law \& Psychiatry, 31 (4), 369-373. doi: $10.1016 / . j . i j p .2008 .06 .001$

Forrester-Jones, R.V.E., \& Grant, G. (1997). Resettlement from Large Psychiatric Hospital to Small Community Residence. Aldershot: Avebury. 
Forrester-Jones, R., Jones, S., Heason, S., \& Di'Terlizzi, M. (2004). Supported employment: a route to social networks. Journal of Applied Research in Intellectual Disabilities, 17 (3), 199-208. doi: $\underline{10.1111 / j .1468-3148.2004 .00199 . x}$

Forrester-Jones, R.V.E., Carpenter, J., Coolen-Schrijner, P., Cambridge, P., Tate, A., Beecham, J., . . .Woof, D. (2006). The social networks of people with intellectual disability living in the community 12 years after resettlement from long-stay hospitals. Journal of Applied Research in Intellectual Disabilities, 19 (4), 285-295. doi: 10.1111/j.1468-3148.2006.00263.x

Forrester-Jones, R.V.E., Carpenter, J., Coolen-Schrijner, P., Cambridge, P., Tate, A., Hallam, A., . . .Wooff, D.(2012). Good friends are hard to find? The social networks of people with mental illness 12 years after deinstitutionalisation. Journal of Mental Health, 21 (1), 4-14. doi: $\underline{10.3109 / 09638237.2011 .608743}$

Fulero, S.M., \& Everington, C. (1995). Assessing competence to waive Miranda rights in defendants with mental retardation. Law and Human Behaviour, 19 (5), 533-543. doi:

\section{$\underline{10.1007 / \mathrm{bf} 01499342}$}

Glaser, W., \& Deane, K. (1999) Normalisation in an abnormal world: a study of prisoners with an intellectual disability. International Journal of Offender Therapy and Comparative Criminology, 43, 338-356. doi: 10.1177/0306624X99433007

Gray, N.S., Fitzgerald, S., Taylor, J., MacCulloch, M.J., \& Snowden, R.J. (2007). Predicting future reconvictions in offenders with intellectual disabilities: The predictive efficacy of VRAG, PCLSV and the HCR-20. Psychological Assessment, 19 (4), 474-479. doi: 10.1037/1040$\underline{3590.19 .4 .474}$ 
Gudjonsson, G., Clare, I.C.H., Rutter, S., \& Pearse, J. (1993). Persons at Risk During Interviews in Police Custody: The Identification of Vulnerabilities. The Royal Commission of Criminal Justice, Research Study no. 12. London: H.M.S.O

Hassiotis, A., Gazizova, D., Akinlonu, L., Bebbington, P., Meltzer, H., \& Strydom, A. (2011). Psychiatric morbidity in prisoners with intellectual disabilities: analysis of prison survey data for England and Wales. British Journal of Psychiatry, 199 (2), 156-157. doi: 10.1192/bjp.bp.110.088039

Hayes, S. (1993). People with an Intellectual Disability and the Criminal Justice System: Appearances Before the Local Courts (Research Report 4). Sydney: New South Wales Reform Commission Report. Retrieved from http://www.lawreform.justice.nsw.gov.au/Pages/Irc/Irc_completed_projects/Irc_completed projects1990_1999/Irc_peoplewithanintellectualdisabilityandthecriminaljusticesystem.aspx

Hayes, S.C. (1996.) People with an Intellectual Disability and the Criminal Justice System: Two Rural Courts. Research Report Number 5. Sydney: NSW Law Reform Commission. Retrieved from http://www.lawreform.justice.nsw.gov.au/Pages/Irc/Irc_completed_projects/Irc_completed projects1990_1999/Irc_peoplewithanintellectualdisabilityandthecriminaljusticesystem.aspx

Holland, S., \& Persson, P. (2011). Intellectual disability in the Victorian prison system: characteristics of prisoners with an intellectual disability released from prison in 2003-2006. Psychology, Crime \& Law, 17 (1), 25-41. doi: 10.1080/10683160903392285

Hill, R.A., \& Dunbar, R.I.M. (2003). Social network size in humans. Human Nature, 14 (1), 53-72. doi:

\section{$\underline{10.1007 / s 12110-003-1016-y}$}

Kebbell, M.R., \& Hatton, C. (1999). People with mental retardation as witnesses in court: a review. Mental Retardation, 37 (3), 179-187. doi: 10.1352/0047-

6765(1999)037<0179:pwmraw>2.0.co;2 
Lindsay, W.R., Carson, D., Holland, A.J., Taylor, J.L., O’Brien, G., Wheeler, J.R., \& Steptoe, S. (2013). Alcohol and its relationship to offence variables in a cohort of offenders with intellectual disability. Journal of Intellectual and Developmental Disabilities, 38, 325-331.

Lindsay, W.R., O’Brien, G., Carson, D., Holland, A.J., Taylor, J.L., Wheeler, J.R., . . Johnston, S. (2010). Pathways into services for offenders with intellectual disabilities: Childhood experiences, diagnostic information and offence variables. Criminal Justice and Behavior, 37 (6), 678-694. doi: $\underline{10.1177 / 0093854810363725}$

Lund, J. (1990). Mentally retarded criminal offenders in Denmark. British Journal of Psychiatry, 156, 726-731. doi: 10.1192/bjp.156.5.726

Lyall, I., Holland, A.J., Collins, S., \& Styles, P. (1995). Incidence of persons with a learning disability detained in police custody: A needs assessment for service development. Medicine, Science and the Law, 35 (1), 61-71. doi: 10.1177/002580249503500113

MacEachron, A. E. (1979). Mentally retarded offenders: prevalence and characteristics. American Journal of Mental Deficiency, 84 (2), 165-76.

Mason, J., \& Murphy, G.H. (2002a). People with intellectual disabilities on probation: an initial study. Journal of Community \& Applied Social Psychology, 12 (1), 44-55. doi: $\underline{10.1002 / \text { casp. } 648}$

Mason, J., \& Murphy, G. (2002b). People with intellectual disabilities on probation: prevalence and outcome. Journal of Intellectual Disability Research, 46 (3), 230-238. doi: 10.1046/j.1365$\underline{2788.2002 .00399 . x}$

McKenzie, K., \& Paxton, D. (2006). Learning Disability Screening Questionnaire. Edinburgh: GCM Records.

Mindham, J., \& Espie, C.A. (2003). Glasgow Anxiety Scale for people with an intellectual disability (GAS-ID): development and psychometric properties of a new measure for use with people 
with mild intellectual disability. Journal of Intellectual Disability Research, 47 (1), 22-30. doi: $\underline{10.1046 / j .1365-2788.2003 .00457 . x}$

Ministry of Justice (2016). Proven Reoffending Statistics Quarterly Bulletin, January to December 2014. London, Ministry of Justice.

Murphy, G.H., Gardner, J. \& Freeman, M. J. (2015). Screening prisoners for intellectual disabilities in three English prisons. Journal of Applied Research in Intellectual Disabilities. doi: 10.1111/jar.12224

Murphy, G., Harnett, H., \& Holland, A.J. (1995). A survey of intellectual disabilities amongst men on remand in prison. Mental Handicap Research, 8 (2), 81-98. doi: 10.1111/i.1468$\underline{3148.1995 . t b 00147 . x}$

Murphy, G.H., \& Mason, J. (2014). Forensic and offending behaviours. In E. Tsakanikos and J. McCarthy (Eds.), Handbook of Psychopathology in Intellectual Disability: Research Practice \& Policy (pp. 281-303). New York: Springer Science.

O'Connell, M.J., Garmoe, W., \& Goldstein, N.E. (2005). Miranda comprehension in adults with mental retardation and the effects of feedback style on suggestibility. Law and Human Behavior, 29 (3), 359-369. doi: 10.1007/s10979-005-2965-y

Perlman, N.B., Ericson, K.I., Esses, V.M., \& Isaacs, B.J. (1994). The developmental handicapped witness: competency as a function of question format. Law and Human Behavior, 18, 171187. doi: 10.1007/BF01499014

Scheyett, A., Vaughn, J., Taloy, M., \& Parish, S. (2009). Are we there yet? Screening processes for intellectual and developmental disabilities in jail settings. Intellectual and Developmental Disabilities, 47 (1), 13-23. doi: $10.1352 / 2009.47: 13-23$ 
Sondenaa, E., Rasmussent, K., Palmstierna, T., \& Nottesstad, J. (2008). The prevalence and nature of intellectual disability in Norwegian prisons. Journal of Intellectual Disability Research, 52 (12), 1129-1137. doi: 10.1111/j.1365-2788.2008.01072.x

Soothill, K., \& Holmes, J. (1981). Finding employment for ex-prisoners: A ten-year follow-up study. The Howard Journal of Criminal Justice, 20 (1-3), 29-36. doi: 10.1111/j.1468$\underline{2311.1981 . t b 00420 \cdot x}$

Talbot, J. (2008). Prisoners' Voices: Experiences of the Criminal Justice System by Prisoners with Learning Disabilities and Difficulties. London: Prison Reform Trust. Retrieved from http://www.prisonreformtrust.org.uk/Portals/0/Documents/No\%200ne\%20Knows\%20repo rt-2.pdf

Tracy, E.M., \& Abell, N. (1994). Social network map: Some further refinements on administration. Social Work Research, 18 (1), 56-60. doi: 10.1093/swr/18.1.56

Vanny, K., Levy, M.H., Greenberg, D.M., \& Hayes, S. (2009). Mental illness and intellectual disability in Magistrates Courts in New South Wales, Australia. Journal of Intellectual Disability Research, 53 (3), 289-297. doi: 10.1111/.1365-2788.2008.01148.x

Wheeler, J.R., Holland, A.J., Bambrick, M., Lindsay, W.R., Carson, D., Steptoe, L., . . O'Brien, G. (2009). Community services and people with intellectual disabilities who engage in antisocial or offending behaviour: referral rates, characteristics and care pathways. Journal of Forensic Psychology \& Psychiatry, 20 (5), 717-740. doi: $\underline{10.1080 / 14789940903174048}$

Wheeler, J., Clare, I.C.H. \& Holland, A.J. (2014) What can social and environmental factors tell us about the risk of offending by people with intellectual disabilities? Psychology, Crime \& Law, 20, 635-658.

Uggen, C. (2000). Work as a turning point in the life course of criminals: A duration model of 
age, employment, and recidivism. American Sociological Review, 65 (4), 529-546. doi: $\underline{10.2307 / 2657381}$ 
Table 1

Sentence lengths and crimes

\begin{tabular}{|c|c|c|c|}
\hline & & $\mathrm{N}$ & $\%$ \\
\hline \multirow[t]{7}{*}{ Sentence length } & Less than 6 months & 15 & 35 \\
\hline & $6-12$ months & 13 & 32.50 \\
\hline & $13-18$ months & 2 & 7.50 \\
\hline & 19-24 months & 1 & 2.50 \\
\hline & More than 24 months & 5 & 15.00 \\
\hline & Couldn't remember & 2 & 7.50 \\
\hline & Total & 38 & 100 \\
\hline \multirow[t]{4}{*}{ Index Crimes } & Convicted of one offence & 30 & 80.00 \\
\hline & Convicted of two offences & 7 & 17.50 \\
\hline & $\begin{array}{l}\text { Convicted of more than } 2 \\
\text { offences }\end{array}$ & 1 & 2.50 \\
\hline & Total & 38 & 100 \\
\hline \multirow[t]{5}{*}{ Category of crime } & $\begin{array}{l}\text { Violent (e.g., fighting, } \\
\text { possessing weapon, arson) }\end{array}$ & 15 & 35.00 \\
\hline & $\begin{array}{l}\text { Non-violent (e.g., theft, } \\
\text { robbery, drugs offence) }\end{array}$ & 8 & 22.50 \\
\hline & $\begin{array}{l}\text { Sexual (e.g., assault, rape, } \\
\text { indecent exposure) }\end{array}$ & 8 & 22.50 \\
\hline & $\begin{array}{l}\text { Offence relating to court } \\
\text { orders (e.g., breaching } \\
\text { restraining order or } \\
\text { probation conditions) }\end{array}$ & 7 & 17.50 \\
\hline & Total & 38 & 100 \\
\hline
\end{tabular}


Table 2

Living situations for the men

\begin{tabular}{lcc}
\hline Type of living situation & $\mathrm{N}$ & $\%$ \\
\hline Living with family/friends/alone & 12 & 31.60 \\
Supported living & 3 & 7.90 \\
Group home with 24hr staff & 3 & 7.90 \\
Probation hostel & 8 & 21.10 \\
Low or medium secure unit & 8 & 21.10 \\
Prison & 4 & 10.50 \\
Total & 38 & 100 \\
\hline
\end{tabular}


Table 3

Activities during the week for the men

\begin{tabular}{lcc}
\hline Times of the week & Number of activities & Range \\
& $M(S D)$ & $0-12$ \\
\hline $\begin{array}{l}\text { Weekdays (out of } 10 \\
\text { half days) }\end{array}$ & $0.32(3.80)$ & $0-3$ \\
$\begin{array}{l}\text { Week evenings (out of } \\
5 \text { evenings) }\end{array}$ & $0.55(0.98)$ & $0-4$ \\
$\begin{array}{l}\text { Weekends (out of } 4 \\
\text { half days) }\end{array}$ & $1.11(1.18)$ & $0-2$ \\
$\begin{array}{l}\text { Weekend evenings } \\
\text { (out of 2 evenings) }\end{array}$ & $0.18(0.51)$ & $0-16$ \\
$\begin{array}{l}\text { Total number of } \\
\text { activities all week }\end{array}$ & $6.16(4.08)$ & \\
\hline
\end{tabular}


Table 4

Men's social networks

\begin{tabular}{lcc}
\hline & $M(S D)$ & Range \\
\hline $\begin{array}{l}\text { People in household, apart } \\
\text { from the man himself } \\
\text { Residential staff contacts }\end{array}$ & $4.10(5.20)$ & $0-20$ \\
$\begin{array}{l}\text { Professional and CLDT contacts } \\
\text { Work/day centre contacts }\end{array}$ & $5.60(7.60)$ & $0-25$ \\
Church/club contacts & $2.40(2.00)$ & $0-8$ \\
Neighbours & $0.74(1.90)$ & $0-30$ \\
Family members & $1.60(3.70)$ & $0-10$ \\
Other friends & $5.70(6.30)$ & $0-20$ \\
$\begin{array}{l}\text { Social acquaintances (e.g., } \\
\text { shop/café contacts) }\end{array}$ & $2.30(5.00)$ & $0-30$ \\
Total network size & $5.80(20.40)$ & $0-30$ \\
\hline
\end{tabular}


Table 5

Satisfaction with life

\begin{tabular}{lcc}
\hline Area of Satisfaction & $M(S D)$ & $\begin{array}{c}\text { Random sample of general } \\
\text { population (Cummins, 1997) }\end{array}$ \\
\hline Things you own & $5.30(1.60)$ & $5.50(0.92)$ \\
Health & $4.80(1.80)$ & $5.20(1.20)$ \\
Achievements in life & $4.60(1.80)$ & $5.10(1.00)$ \\
Close relationships & $5.30(1.90)$ & $5.60(1.10)$ \\
How safe you feel & $5.20(1.80)$ & $5.60(0.90)$ \\
Doing things outside the home & $4.80(1.80)$ & $5.30(1.00)$ \\
Your own happiness & $4.90(1.40)$ & $5.30(1.10)$ \\
\hline
\end{tabular}

